Supplement of Saf. Nucl. Waste Disposal, 1, 241-242, 2021

https://doi.org/10.5194/sand-1-241-2021-supplement

(c) Author(s) 2021. CC BY 4.0 License.

Supplement of

\title{
International safeguards for the final disposal of spent nuclear fuel - why, what and how
}

Irmgard Niemeyer et al.

Correspondence to: Irmgard Niemeyer (i.niemeyer@fz-juelich.de)

The copyright of individual parts of the supplement might differ from the article licence. 


\section{INTERNATIONAL SAFEGUARDS FOR THE FINAL DISPOSAL OF SPENT NUCLEAR FUEL - WHY, WHAT AND HOW}

11.11.2021 I I. NIEMEYER, K. AYMANNS, G. DEISSMANN, D. BOSBACH Institute of Energy and Climate Research, IEK-6: Nuclear Waste Management

SESSION 4A EN

Activities in international research

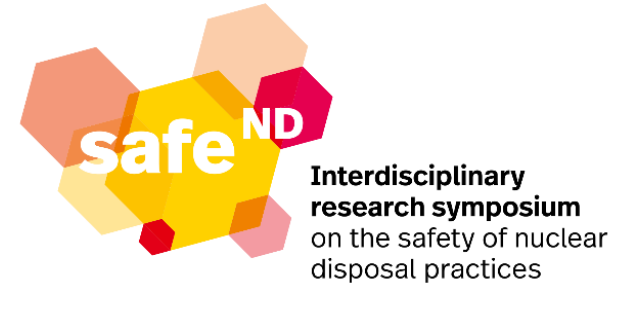

У JüLLCH 


\section{NUCLEAR SAFEGUARDS}

To deter the spread of nuclear weapons by the early detection of the misuse of nuclear material or technology
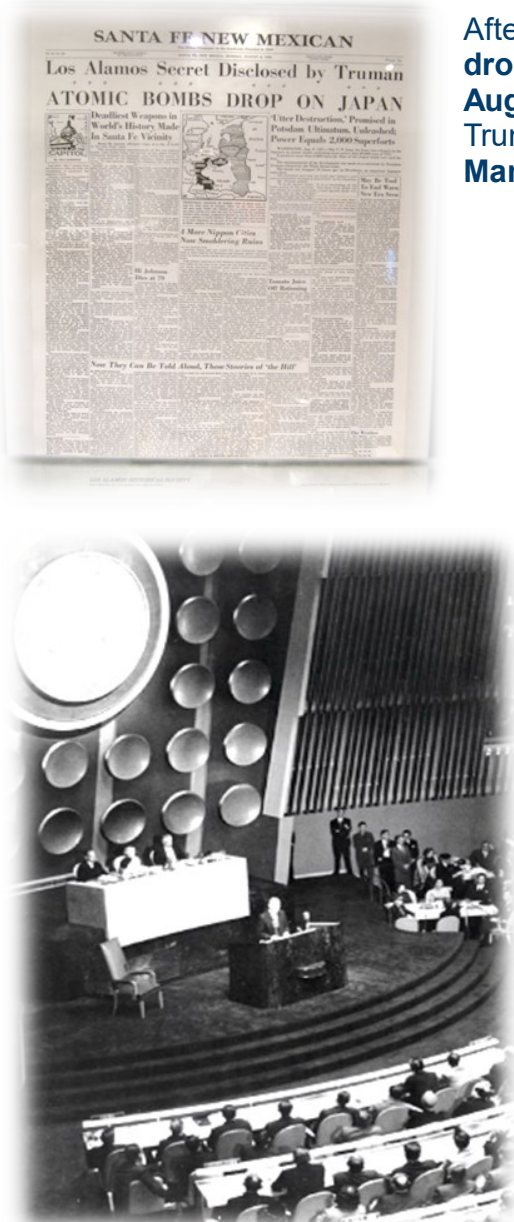

After the first nuclear bomb was dropped on Hiroshima on 6

August 1945, US-President Harry

Truman unveiled the top-secret

Manhattan Project.

Treaty on the Non-Proliferation of

Nuclear Weapons (NPT), 1970

Nonproliferation (Art. I \& II), Safeguards (Art. III)

QIAEA

Atoms for Peace Speech US-President Dwight D. Eisenhower, UN Genera Assembly, 8 December 1953
Generic safeguards objectives

To detect any diversion of declared nuclear material at declared facilities or locations outside facilities where nuclear material is customarily used (LOFs)

To detect any undeclared production or processing of nuclear material at declared facilities or LOFs of nuclear energy (Art. IV \& V)
Disarmament (Art. VI)
To detect any undeclared nuclear material or activities in the state as a whole

\section{S JüLICH




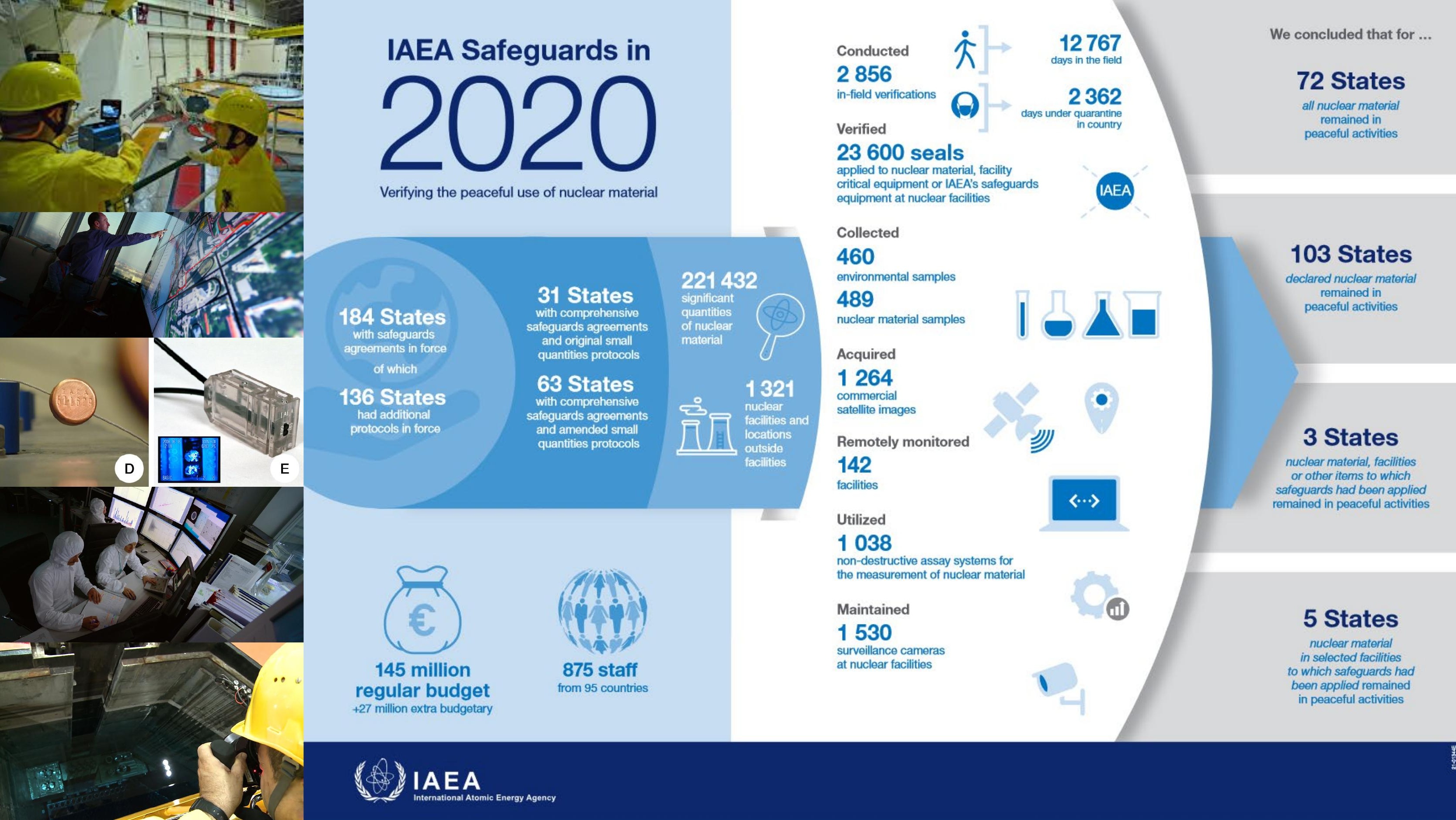




\section{INTERNATIONAL COLLABORATION IN SAFEGUARDS}

\section{Member State Support Programmes in IAEA Safeguards}
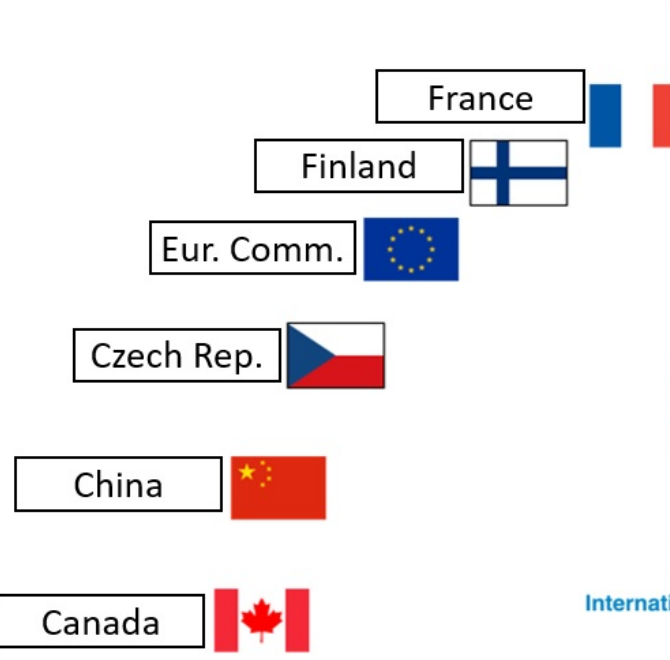

Brazil 8

$$
\begin{aligned}
& \hline \text { Belgium } \\
& \hline \text { Australia } \\
& \text { Argentina } \\
& \hline
\end{aligned}
$$

Germany
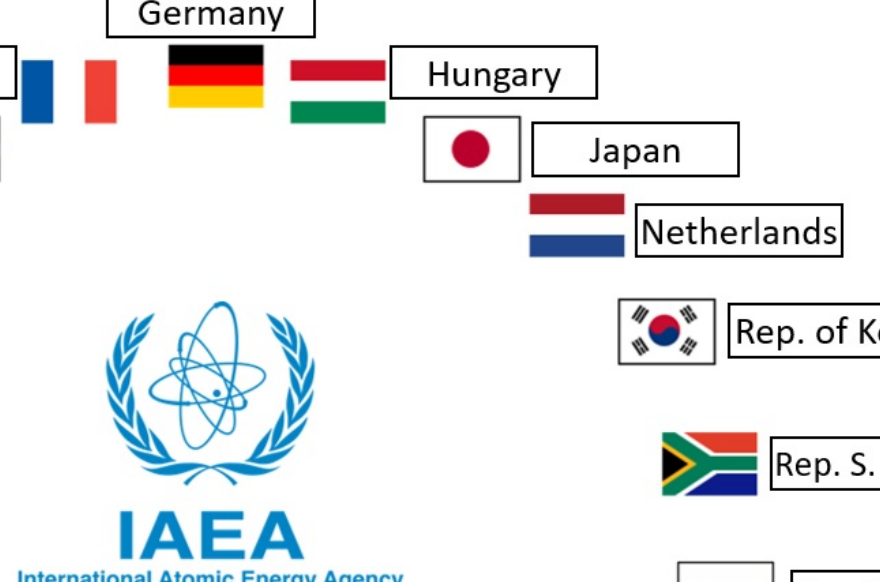

21 Member States' Support Programmes

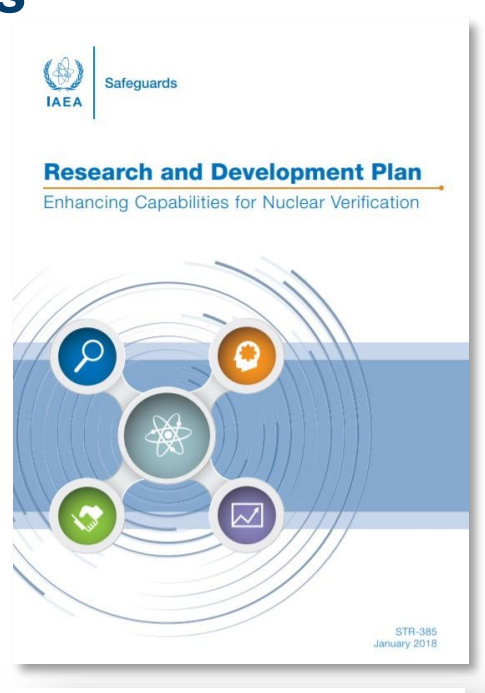

$$
\left(\left.\begin{array}{l}
(1) \\
\text { IAEA }
\end{array}\right|_{\text {satogurars }}\right.
$$
Development and Implementation
Support Programme for Nuclear Verification 2020-2021

España (Spain)

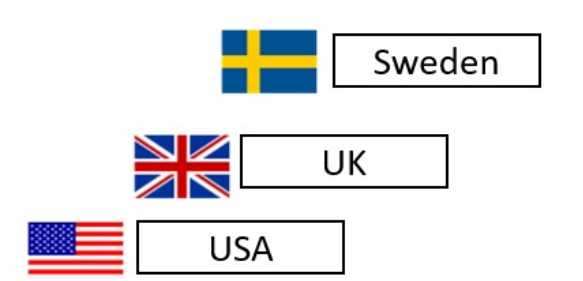

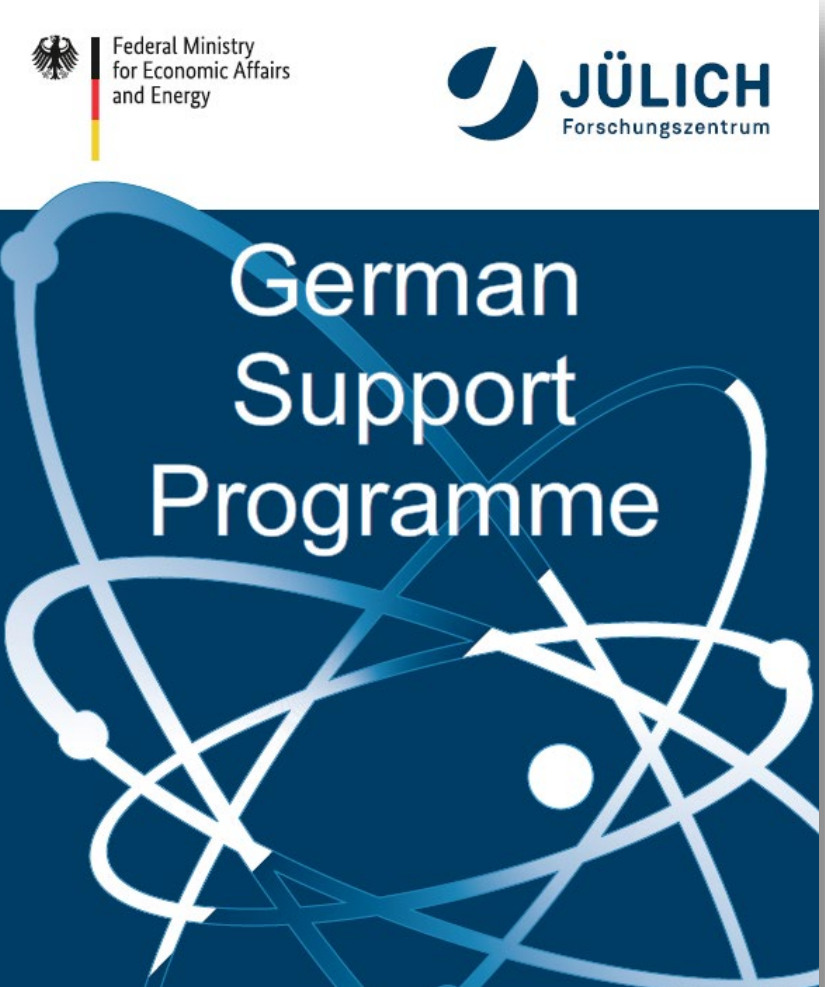

Contributing to IAEA Safeguards since 1978 


\section{INTERNATIONAL COLLABORATION IN SAFEGUARDS}

\section{Safeguarding final disposal of spent nuclear fuel - Overview}

1988: IAEA

Advisory

Group on

Safeguards

related to

Final Disposal

\author{
1994-1998 \\ IAEA SAGOR \\ Working \\ Group
}

\author{
2006-2017: \\ IAEAASTOR \\ Working \\ Group
}

2020:

ESARDA

Working

Group on

Final Disposal

\begin{abstract}
1991: IAEA
Consultants'

Meeting on

Safeguards

for Final

Disposal
\end{abstract}

1999-2006

IAEA Group

of Experts

(SAGOR II)
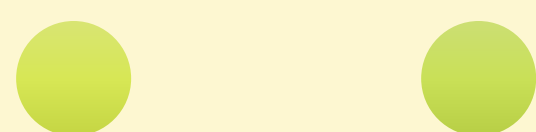

2018-2019:

Consolidation

of ASTOR

and SAGOR tasks

SAGOR : Safeguards for Geological Repositories

ASTOR: Application of Safeguards to Geological Repositories

ESARDA: European Safeguards Research and Development Association 


\section{SAGOR (1994-1998) \& SAGOR II (1999-2006)}

Safeguards for Geological Repositories: Reports and activities

STR-312 (1998): Safeguards

for the Final Disposal of Spent

Fuel in Geological Repositories

SAGOR
STR-324 (2000): The Use of Geophysical Techniques for Safeguarding Geological Repositories

STR-338 (2003): Interface Issues and Interaction Between Safeguards and Radioactive Waste

SAGOR II Management in the Context of Geological Repositories 


\section{ASTOR (2006-2017)}

\section{Application of Safeguards to Geological Repositories: Reports and activities}

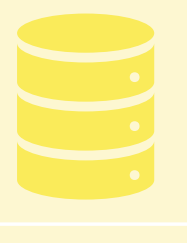

ASTOR

\section{Technology principle and} brief description

- Technology readiness level

- Technology limitations

STR-384 (2017):

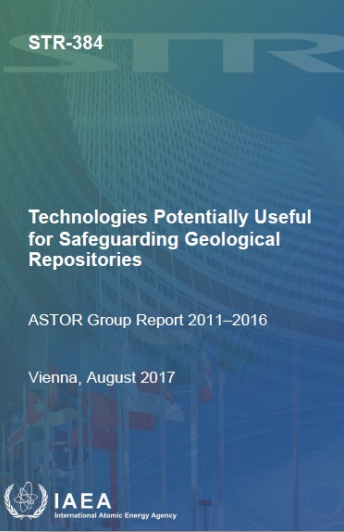

- Estimated costs Technologies

Potentially Useful for Safeguarding Geological Repositories
- Sustainability, standardization, supply chain

- Ease of use / operator skill / infrastructure needs

- Data validation / authentication

- Expected 'Alarm' rates

\section{Technologies}

- Design Information Verification (DIV)

- Non-destructive analysis (NDA) verification

- Containment and surveillance (C/S) measures and canister ID

- Satellite imagery

- Geophysical techniques (i.a. seismic detection, directional radar technology)

- Long-term management of safeguards-related data 


\section{DESIGN INFORMATION VERIFICATION (DIV)}

\section{Detection of undeclared constructions}
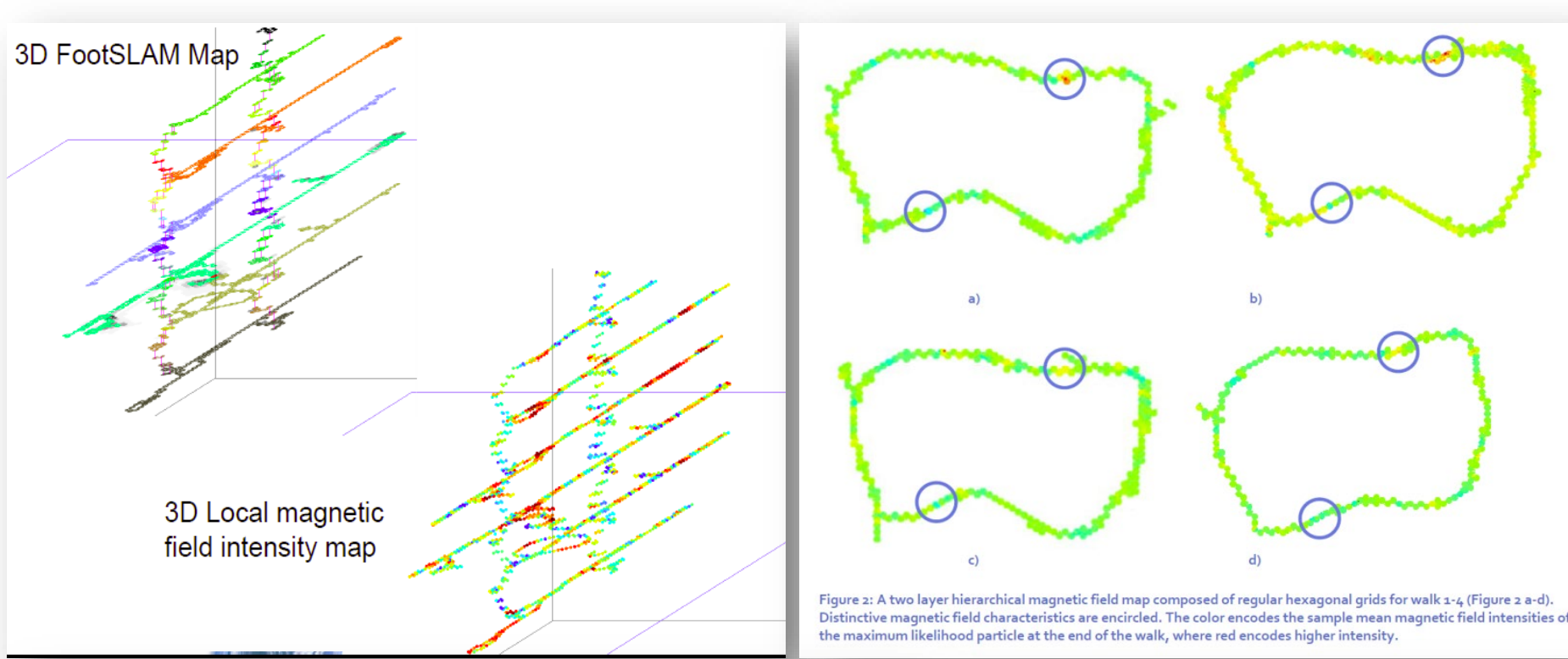

Simultaneous location and mapping (SLAM) (GER-DLR)

S. Kaiser, E. Munoz Diaz, P. Robertson (2016): Study on the Feasibility of FootSLAM for Use During Safeguards Verification Activities. JOPAG/03.16-PRG-423

S. Kaiser, E. Munoz Diaz (2016): FootSLAM2: Enhancing IAEA's Navigation Algorithm for use in Complementary Access

Inspections. JOPAG/03.16-PRG-424
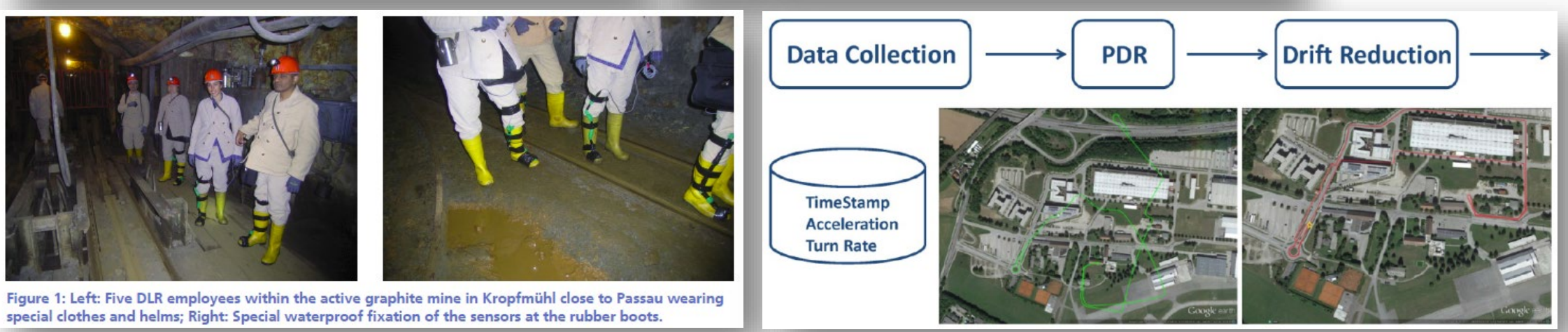


\section{SATELLITE IMAGERY (SI)}

\section{Change detection, deformation analysis}

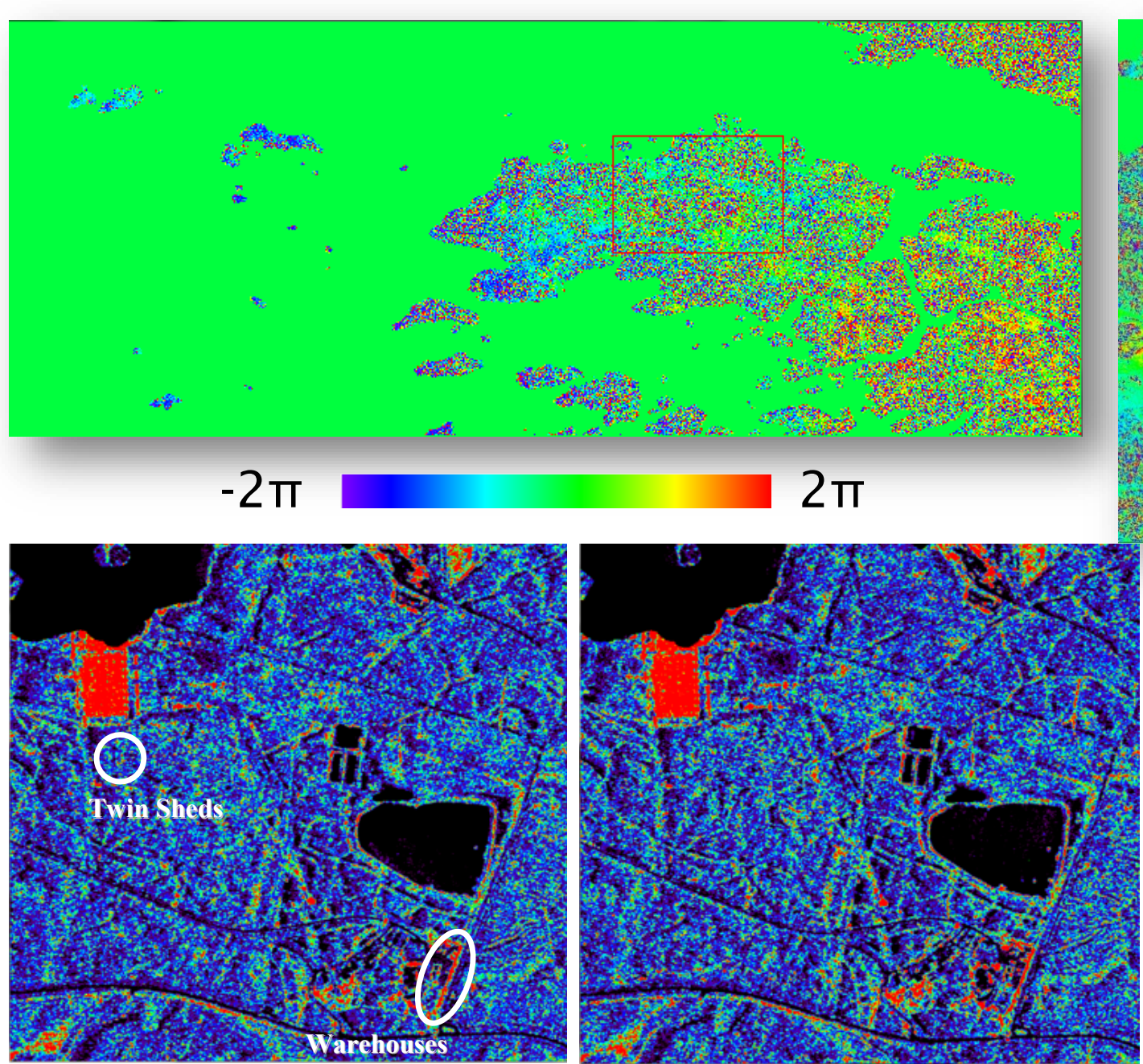

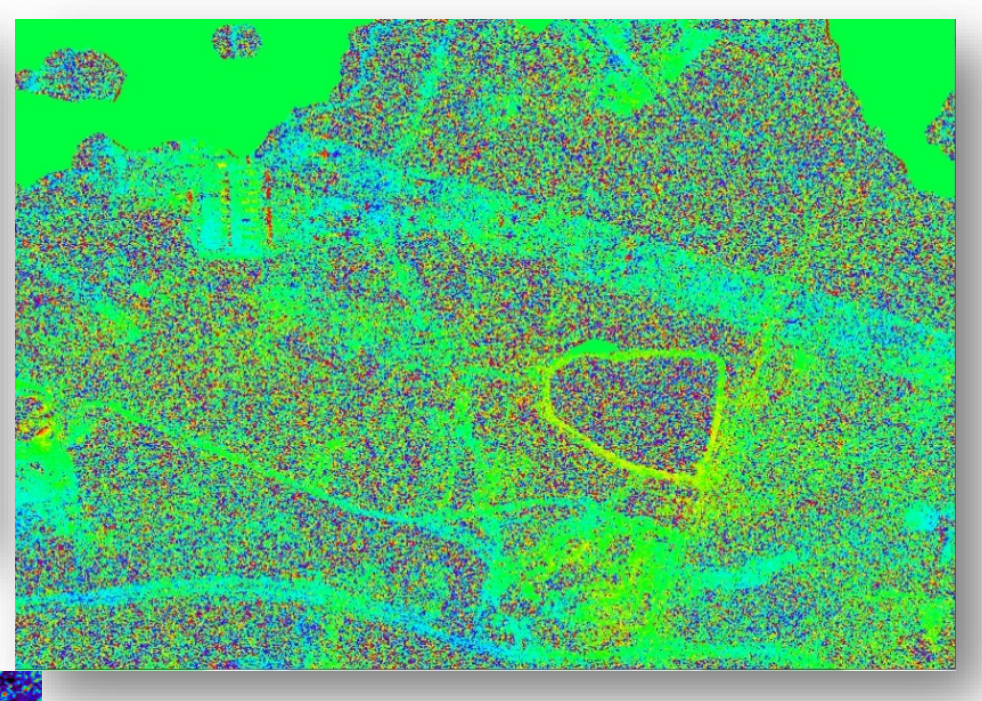

TerraSAR-X images acquired at May 23 (right) and June 3 (left)

Top: Interferogramm Left: Color-coded backscatter intensity

low
TerraSAR-X

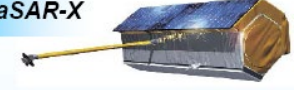

Application of SAR interferometry and non-coherent change detection techniques (CAN/FIN/GERJülich/JPN)

I. Niemeyer, O. Okko, B. Moran, D. Davainius (2018): Safeguarding Geological Repositories Using

Geophysical Monitoring and Satellite Imagery. Proc. of the INMM Annual Meeting 2018 


\section{GEOPHYSICAL TECHNIQUES}

\section{Detection of undeclared / unauthorised activities}
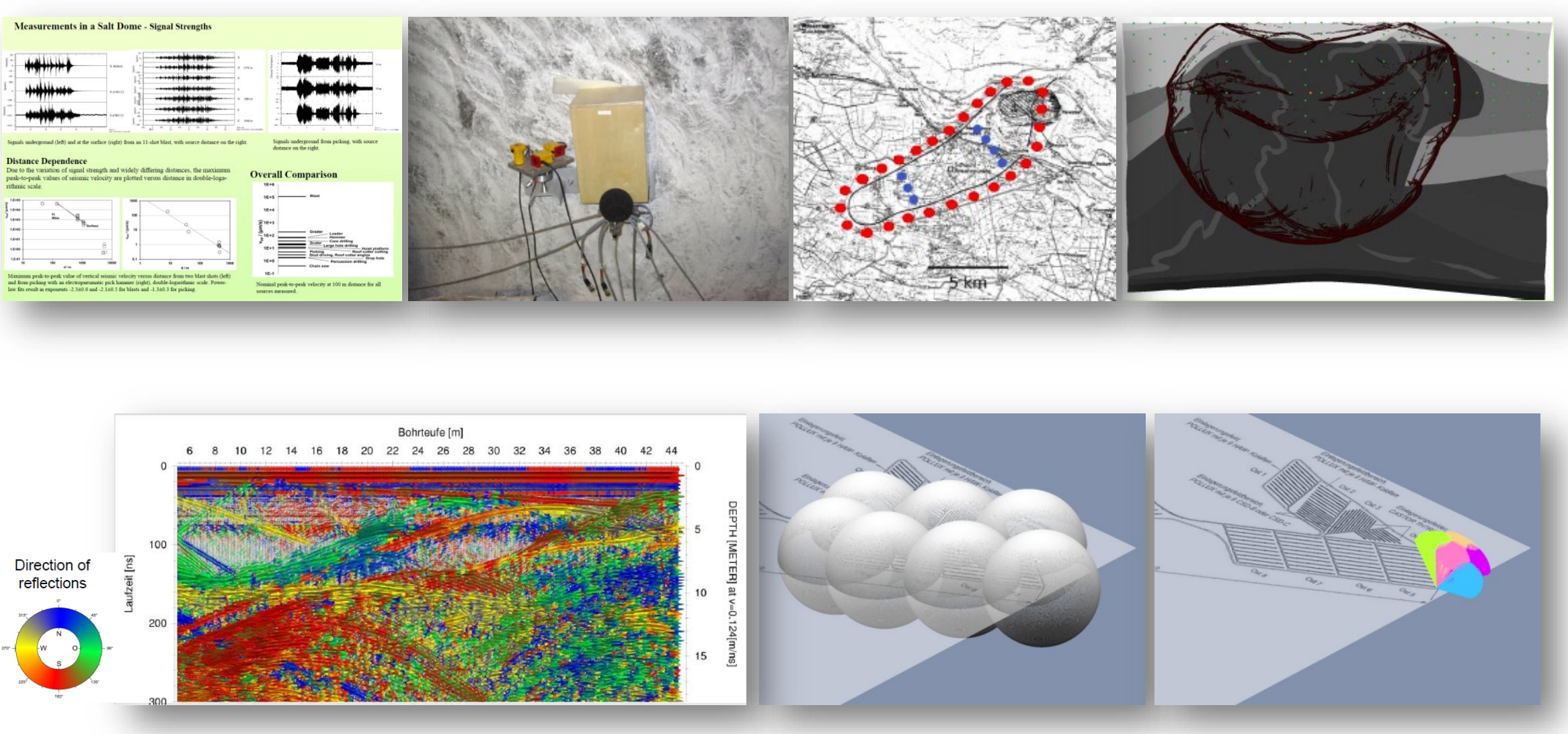

Acoustic and seismic monitoring (GER-TU Dortmund)

J. Altmann, H. Kühnicke (2015): Acoustic and Seismic Measurements for the Detection of Undeclared Activities at Geological Repositories. Results from the Gorleben Exploratory Mine. JOPAG/11.13-PRG-404

J. Altmann (2015): Modelling of Seismic-Wave Propagation at a Salt Dome. Final Report. JOPAG/12.15PRG-422

\section{Directive underground radar (GER-DMT)}

C. Holst, D. Orlowsky, S. Uchtmann (2017): Applicability of the directional radar technology for safeguards monitoring nuclear repositories in geological formations. Proc. ESARDA Symposium, Düsseldorf, 2017 


\section{CONSOLIDATION OF SAGOR AND ASTOR RECOMMENDATIONS (2018-2019)}

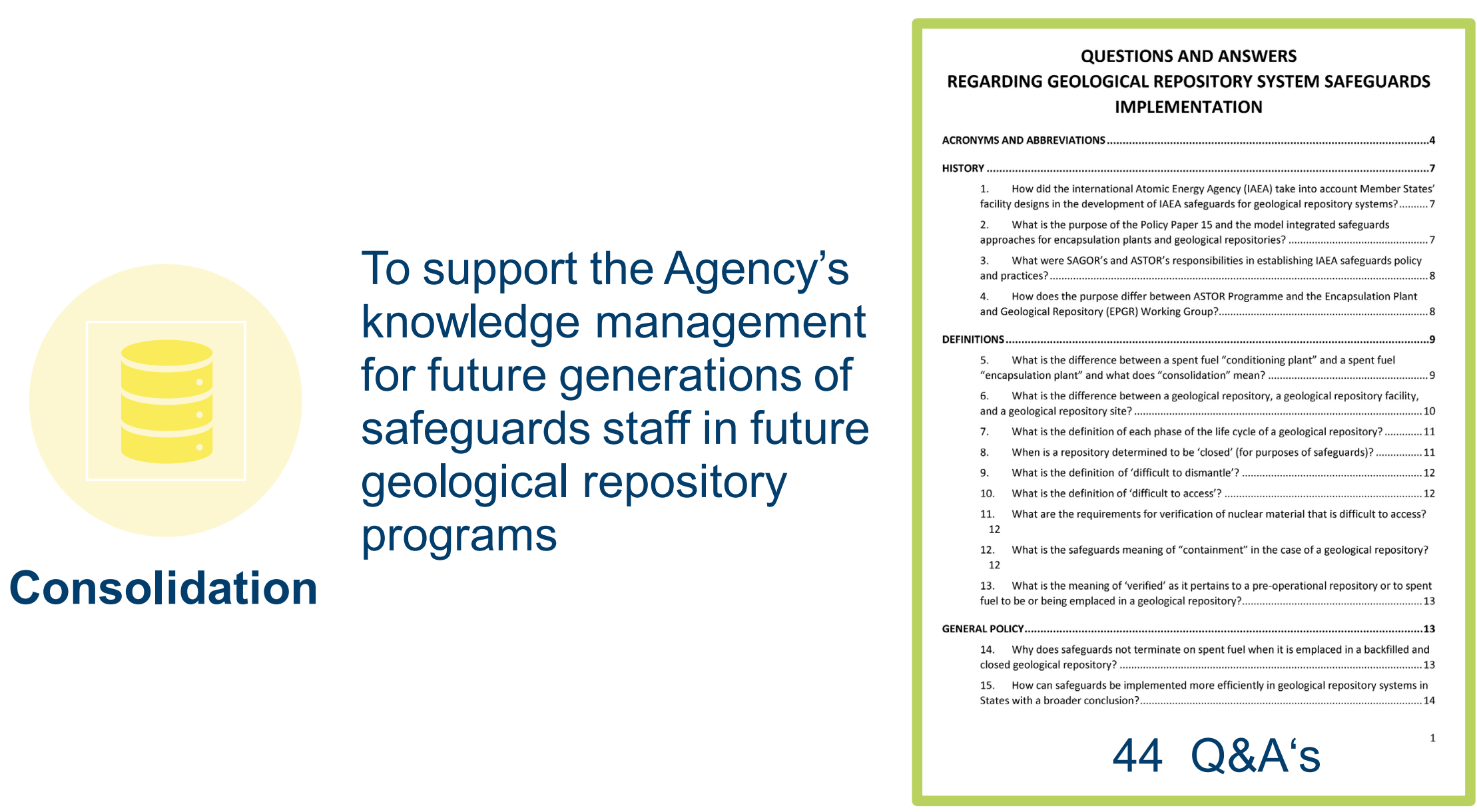

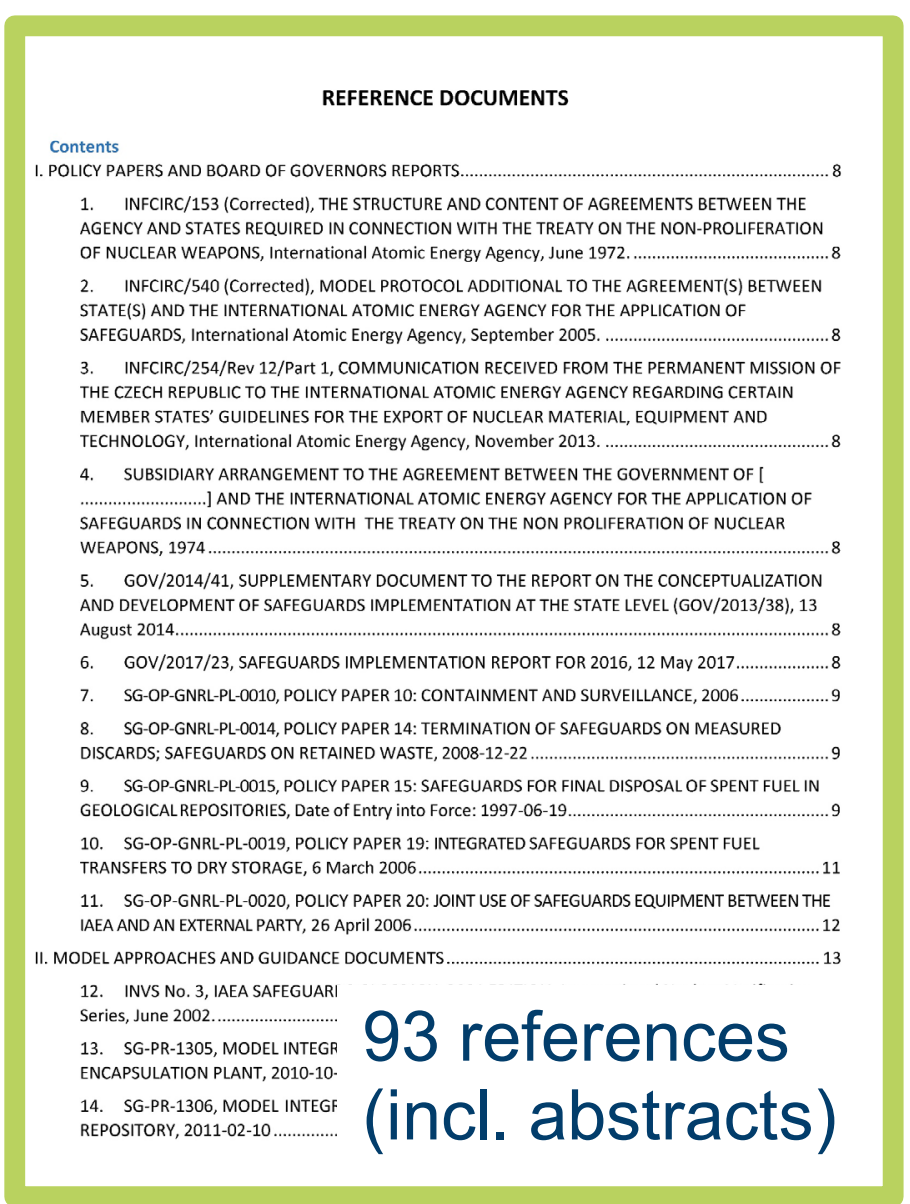

J 


\section{CONSOLIDATION OF SAGOR AND ASTOR RECOMMENDATIONS (2018-2019): ACHIEVEMENTS}

\section{Performed diversion path \\ Identified potential} analysis for generic encapsulation plants and geological repositories

Developed and assessed a safeguards approach based on IAEA Safeguards Criteria safeguards detection points for each facility type and operating phase

Provided input and review of IAEA safeguards policy for spent fuel disposal
Identified facility-specific technical objectives

Identified research and development needs and reviewed status of related development tasks
Identified safeguards measures that could be used for each facility

Supported preparation of a model integrated safeguards approach for each facility type

\section{Consolidation}

Supported preparation and testing of a design information questionnaire for each facility type
Provided input to a safeguards implementation 'road map' developed by the IAEA Department of Safeguards
Issued a report on the status of technologies that could be used for

safeguarding encapsulation plants and geological repositories (STR-384) 


\section{FURTHER R\&D NEEDS}

\section{Technologies}

Establish performance requirements for the design of relevant safeguards technologies

Develop and test appropriate safeguards equipment

\section{Implementation}

Determine specific information needs of stakeholders and develop appropriate guidance

Develop safeguards approaches under the State-level concept

Develop further approaches on 'Safeguards-by-Design' and the 'Safety-SecuritySafeguards' (3S)
Data and information management

Develop approaches on how information about disposed spent fuel and high-level nuclear waste should be managed, handled, organized, archived, read, interpreted, and secured for the long term (for centuries after repository closure and beyond) 


\section{SAFEGUARDING A GEOLOGICAL REPOSITORY IN GERMANY}

\section{Responsibilities}

Federal Ministry
for Economic Affairs and Energy
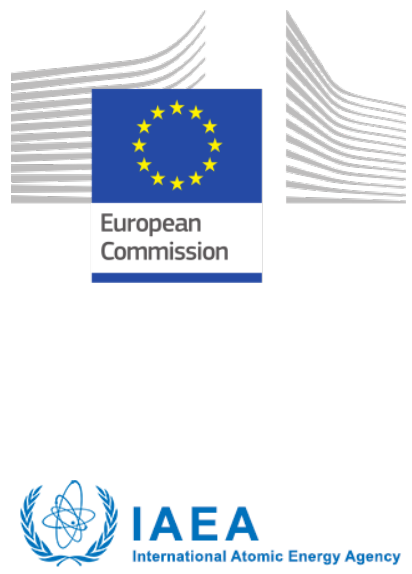

Germany does not have a national safeguards authority of its own and does not carry out safeguards inspections on its own. Sovereign rights in this field were transferred to the EC (DG Energy, EURATOM). EURATOM is the owner of all nuclear fuel in the EU.

The Federal Ministry for Economic Affairs and Energy (BMWi) holds the overall political responsibility as to maintaining any interferences of safeguards activities with domestic regulations.

EURATOM acts as multinational safeguards authority and is the direct contact for the IAEA on the one hand and the operators on the other within the framework of the verification agreement between the IAEA, EURATOM and the EU member states (INFCIRC/193). 


\section{REFERENCE CONCEPT FOR NUCLEAR MATERIAL SAFEGUARDS IN A GEOLOGICAL REPOSITORY FOR SPENT NUCLEAR FUEL (1993)}

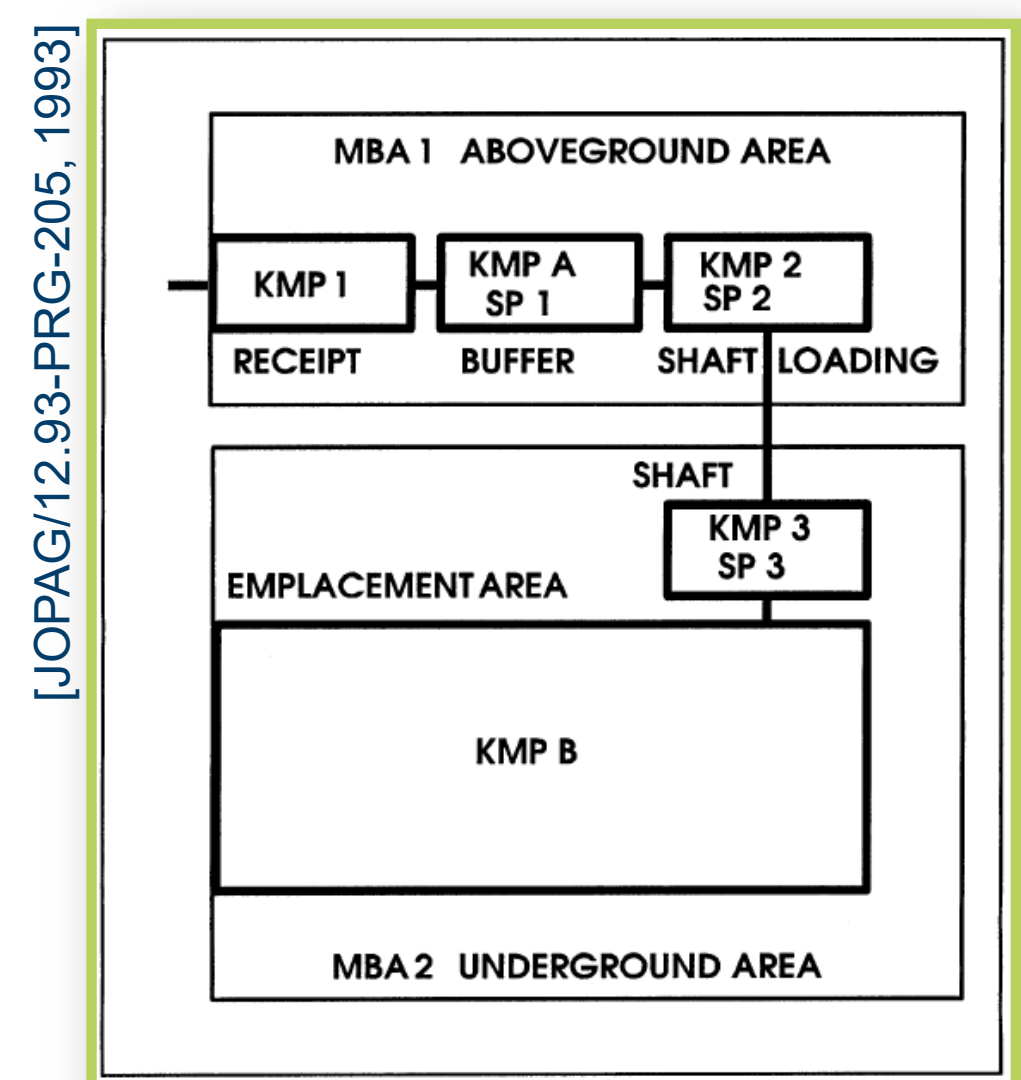

Figure 4: Safeguards concept for final disposal in a geological repository
KMP: Key Measurement Point

MBA: Material Balance Area

SP: $\quad$ Strategic Point

MBA 2:

- Accounting and reexamination of the plant design data

- No containment/surveillance measures

- No inspection activities

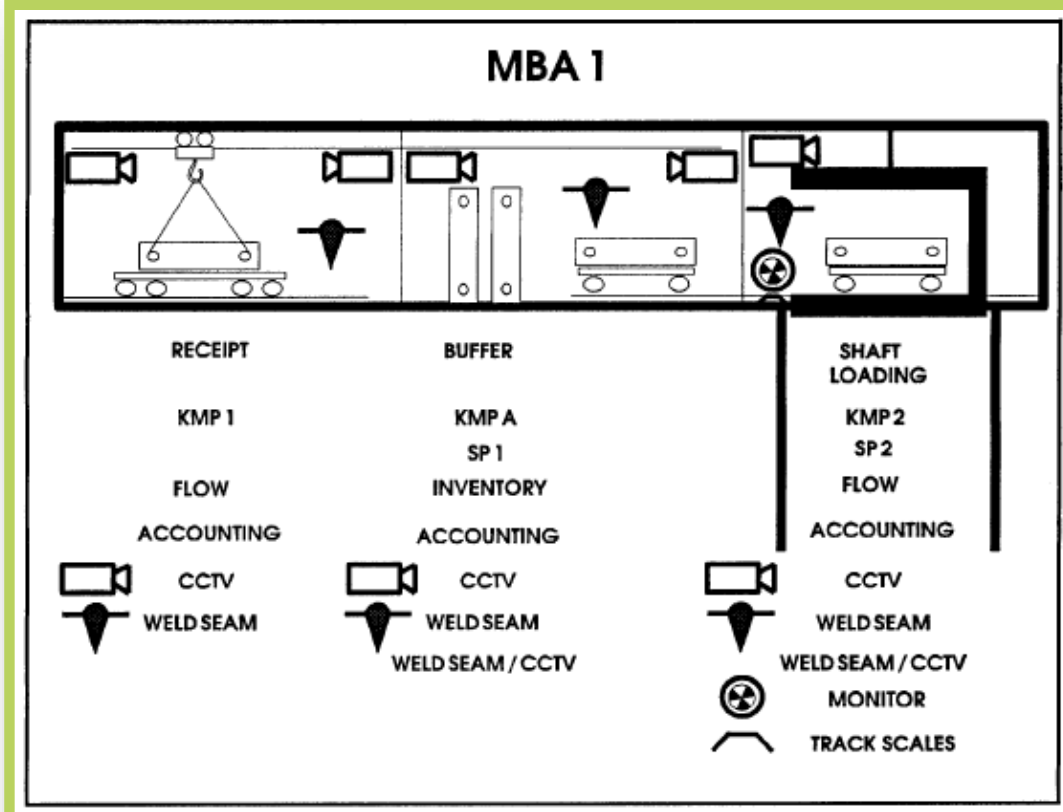

Figure 5: Possible safeguards measures for MBA 1 


\section{UPDATING THE SAFEGUARDS CONCEPT}

\section{Taking into account the 2010 safety requirements (recoverability, retrievability)}
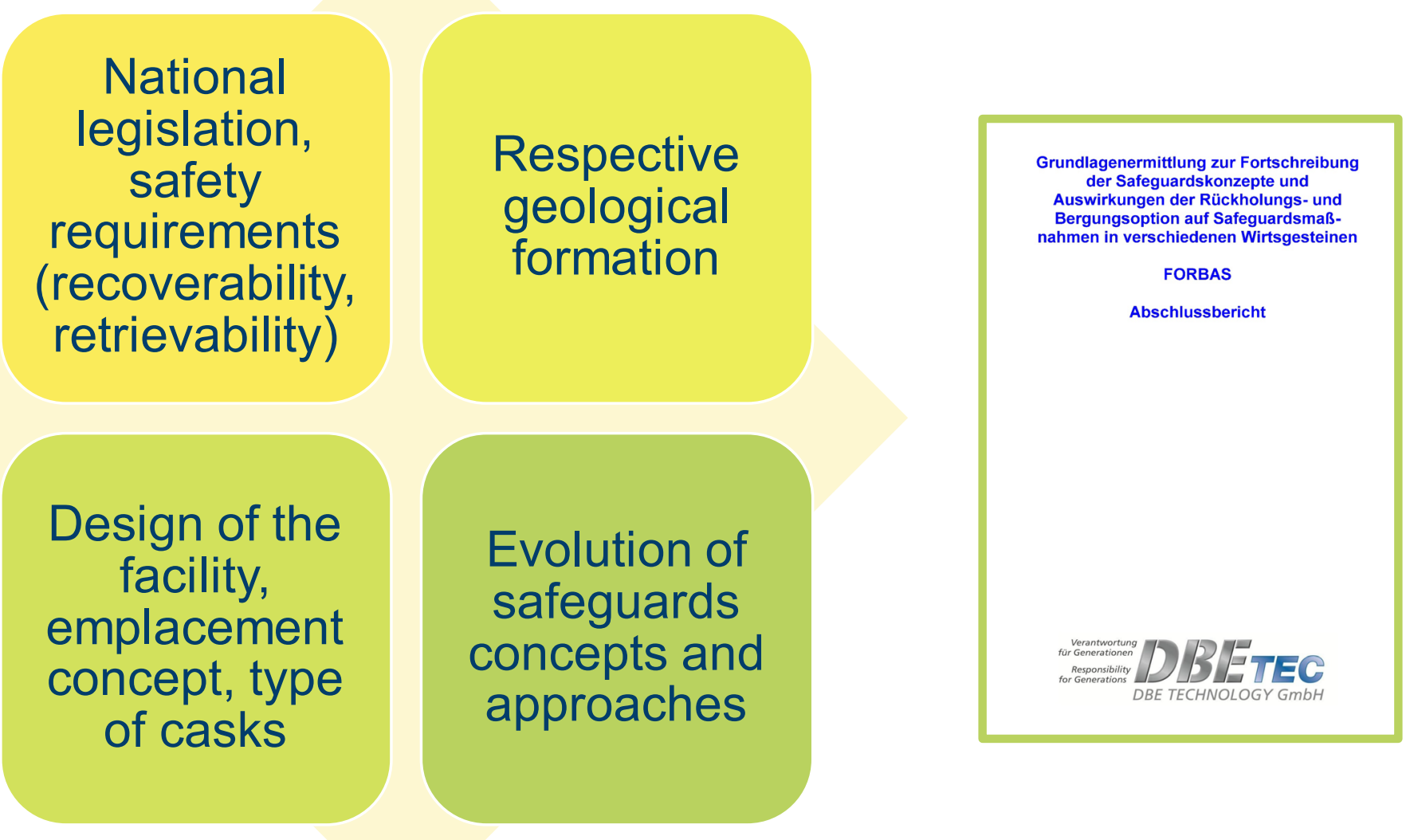

The State-level approach (SLA) for Germany will address the safeguards measures and activities for the geological repository. The given SLA for Germany will be updated in the different lifecycle phases of the repository. 


\section{Thank you for your attention.}

Dr. Irmgard Niemeyer

Nuclear Waste
Management

Institute of Energy and Climate Research

Email: i.niemeyer@fz-juelich.de 